\title{
Analysis on the Dilemma of College Teaching Team Construction from the Perspective of Game Theory
}

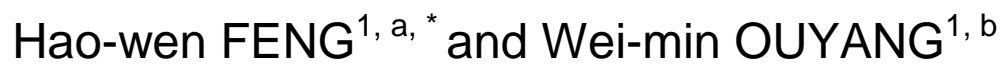 \\ ${ }^{1}$ Shanghai University of Political Science and Law, China \\ ªfenghaowen@shupl.edu.cn, ${ }^{b}$ oywm@shupl.edu.cn \\ ${ }^{*}$ Corresponding author
}

Keywords: Game theory, Teaching team, Strategy.

\begin{abstract}
The construction of college teaching team is an important measure to improve the quality of teaching in Colleges. The construction of college teaching team needs the input of various resources including manpower, funds and system. Because of the defects of "appreciate scientific research and despise teaching" in the long term, the college and the teachers have a strong positive preference for scientific research and a negative preference for teaching, college and teachers do not have enough motivation to put resources into teaching. From the perspective of game theory, we analyze the dilemma caused by the conflict of interests between college and teachers in the allocation of educational resources, and put forward the corresponding countermeasures to break the dilemma.
\end{abstract}

\section{Introduction}

In order to promote the improvement of teaching quality, the ministry of education launched the "college teaching quality and teaching reform project", which requires colleges to strengthen the construction of teaching team. The construction of college teaching team is an important measure to improve the quality of teaching in Colleges, which is a fundamental important work. The construction of college teaching team needs the input of various resources including manpower, funds and system. Because of the defects of "appreciate scientific research and despise teaching" in the long term, the college and the teachers have a strong positive preference for scientific research and a negative preference for teaching, college and teachers do not have enough motivation to put resources into teaching. From the perspective of game theory, we analyze the dilemma caused by the conflict of interests between college and teachers in the allocation of educational resources, and put forward the corresponding countermeasures to break the dilemma.

\section{Game Analysis on the Allocation of Educational Resources between College and Teaching Team}

College allocate education resources to teaching teams, which aims to improve teaching quality to strengthen the construction of teaching team and improve the quality of education in the college. However, teachers have a strong positive preference for scientific research and a negative preference for teaching, teaching team tends to put the education resources allocated to teaching team into improving research work and office environment instead of improving the quality of education. There exists a risk of receiving less than expected results in the allocating education resources to teaching team in colleges. Because of the university itself is actually negative bias in teaching, in 
order to avoid the risk, college will tend to be cautious in allocating resources to teaching teams, but cannot too cautious. If college is too cautious in allocating resources to teaching team, teaching team will be lack of the necessary resources, which leads to the low level of the construction of teaching team, which this will eventually lead to the decrease of the quality of teaching, college will not complete the task of "quality engineering" issued by ministry of education. So, college has a dilemma of "allocation" and "non allocation" in the allocating resources to teaching team.

Teaching team naturally wants to get more resources from college. However, after obtain resources, teaching team has not necessarily a big motivation to put the resources into teaching. Due to the constraints of the management mechanism, teaching team cannot freely transfer the resources to the scientific research and other aspects. If the teaching team did not put the resources allocated by college into the construction of teaching team, the teaching level failed to be improved, teaching quality has stalled, or even declined, they will face the pressure of the college.

And meanwhile, if college found that teaching team improperly use or divert resources through audit of the use of funds, college will give a bad review to the teaching team, and will reduce or even stop the allocation of resources. This will make a great negative impact on the teaching team.

However, because the teacher's behavior pattern of "appreciate scientific research and despise teaching" is difficult to change, and because of information asymmetry, college is not easy to observe the actual behavior of the teaching team, teachers are still likely to take different actions with the purpose of college allocating resources, for example, put the part or even all of the resources into scientific research or office conditions improvement. So, teaching team has a dilemma of "for" and "not for" in the using of the allocated resources.

According to the above analysis, we assume that the strategy choices for college are "allocate" and "not allocate", and the strategy choices for teaching team are "for" and "not for" in the game between college and teaching team. So, there are four cases as follows.

Case 1: college selects the strategy of "allocate", teaching team selects the strategy of "for".

In this case, because teaching team use the allocated resources for the construction of teaching team, teaching quality will be improved, the teaching team will get a good evaluation, assume the profit of teaching team is 2.Because of the improvement of the quality of teaching will give the school a better reputation, assume the profit of college is 3 .

Why the profit of teaching team is lower than the profit of college, because teaching team takes time and money and other resources into teaching will inevitably affect its investment in scientific research and services, the overall benefits of the teaching team will be reduced.

Case 2: college selects the strategy of "allocate", teaching team selects the strategy of "not for". In this case, because teaching team do not use the allocated resources for the construction of teaching team, but for scientific research and services, teaching quality will not be improved, but get better profits in scientific research and services, assume the profit of teaching team is 4.Because teaching quality has not be improved, college has not received the expected effect of allocating the resources to teaching team, the allocated resources are wasted, we assume the profit of college is -5 .

Case 3: college selects the strategy of "not allocate", teaching team selects the strategy of "for". In the case of college not allocating resources for the construction of 
teaching team, teaching team adhere to the construction of teaching team, the reputation of teaching team will be improved, teaching quality will also be improved to some extend, due to damage its scientific research and service revenue, thus do more harm than good, we assume the profit of teaching team is -1.Because not allocating resources to the teaching team will bring college a bad effects of not valuing education, and will bring a bad reputation, we assume the profit of college is -1 .

Case 4: college selects the strategy of "not allocate", teaching team selects the strategy of "not for". In the case of college not allocating resources for the construction of teaching team, teaching team give up the construction of teaching team, the construction of teaching team will stop, teaching quality will not be improved, we assume the profit of teaching team is 0 .Because not allocating resources to the teaching team will bring college a bad effects of not valuing education, and will bring a bad reputation, we assume the profit of college is -1 .

Based on the above description, the game's payoff matrix is shown in Table. 1.

Table 1: the game's payoff matrix between college and teaching team

\begin{tabular}{|l|c|c|c|}
\hline \multirow{2}{*}{ college } & \multicolumn{3}{|c|}{ teaching team } \\
\hline & & for & Not for \\
\cline { 2 - 4 } & allocate & 3,2 & $-5,4$ \\
\cline { 2 - 4 } & not allocate & $-1,-1$ & $-1,0$ \\
\hline
\end{tabular}

According to the above game payoff matrix, we discuss the strategy choice of college and teaching team respectively.

First, consider the strategy choice of college in the game between college and teaching team. If teaching team choose "for" strategy, then the profit of college in choosing "allocate" strategy is 3 and the profit of college in choosing "not allocate" strategy is -1 , because $3>-1$, the choice of "allocate" strategy is college's optimal reaction under teaching team taking "serious" strategy; If teaching team choose "not for" strategy, then the profit of college in choosing "allocate" strategy is -5 , and the profit of college in choosing "not allocate" strategy is -1 , because $-1>-5$, the choice of "not allocate" strategy is college's optimal reaction under teaching team taking "not for" strategy. Therefore, college has no dominant strategy in the game between college and teaching team, whose optimal reaction depends on the strategies taken by teaching team. If teaching team take "for" strategy, college had better to take "allocate" strategy; If teaching team take "not for" strategy, college had better to take "not allocate" strategy.

Second, consider the strategy choice of teaching team in the game between college and teaching team. If college choose "allocate" strategy, then the profit of teaching team in choosing "for" strategy is 2, and the profit of teaching team in choosing "not for" strategy is 4 , because $4>2$, the choice of "not for" strategy is teacher's optimal reaction under college taking "allocate" strategy; If college choose "not allocate" strategy, then the profit of teaching team in choosing "for" strategy is -1 , and the profit of teaching team in choosing "not for" strategy is 0 , because $0>-1$, the choice of "not for" strategy is teaching team's optimal reaction under college taking "not allocate" strategy. Therefore, whether the college's evaluation strategy is "allocate" or "not allocate", the dominant strategy of teaching team in the game between college and teaching team is "not for".

Because the dominant strategy of teaching team in the game between college and teaching team is "not for", teaching team will always choose "not for" strategy in this 
game, and college will then choose "not allocate" strategy. So, the Nash equilibrium of the game is ("not allocate", "not for").

Because the Nash equilibrium will be injurious to the long-term interests and reputation for running college, this is the situation that the school is not willing to appear.

On the one hand, because teachers have a natural sense of mission on education teaching, they in their hearts are hoping to strengthen the construction of teaching team to improve their own teaching level and the quality of teaching, so in the actual using the resources allocated by college, teaching team may use the resources for the construction of teaching team. On the other hand, if the teaching team always choose "not for" strategy, then college will take "not allocate" strategy, which will result in adverse consequences on both sides. As a rational being, teaching team is impossible to consistently take a fixed strategy, otherwise, they will be easily penetrated and at a disadvantage position, the rational strategy choices are generally random, whose purpose is to make the expected profits of college under different strategies, thus forcing college has no optimal reaction under all kinds of teaching team's strategies.

Based on the above observations, we assume that the probability of teaching team to choose "for" strategy is $\mathrm{p}$, then the probability of teaching team to choose "not for" strategy is 1-p. Therefore, the expected profits of college under "allocate" strategy is $3 p+(-5)(1-p)$, the expected profits of college under "not allocate" strategy is- $\mathrm{p}+(-1)(1-\mathrm{p})$.

To make the two expressions equal, $3 p+(-5)(1-p)=-p+(-1)(1-p)$.

We will get: $\mathrm{p}=1 / 2$.

When $p>1 / 2$, the optimal reaction of college is "allocate" strategy. As long as the probability of team choosing "for" the strategy is more than $1 / 2$, college should choose the "allocate" strategy to actively invest educational resources to teaching team.

When $\mathrm{p}<1 / 2$, the optimal reaction of college is "not allocate" strategy. As long as the probability of team choosing "for" the strategy is less than $1 / 2$, college should choose the "not allocate" strategy not to invest educational resources to teaching team.

Therefore, whether college allocate educational resources to teaching team depends on how much will teaching team invest the allocated education resources for the construction of teaching team.

Countermeasures for the dilemma of teaching team construction

Based on the above analysis, if college wishes to the allocated education resources to be used for the construction of teaching team, college must improve the positive motivation for teaching team to invest the construction of teaching team. And if college wants to encourage teaching team to improve their positive motivation to invest the construction of teaching team, college must improve the profit on teaching team construction, change the payment function about the both sides of the game. Therefore, we propose to take the following measures:

To change the unitary criteria for teacher evaluation, according to different disciplines and resources, college set different evaluation criteria for teachers. The actual situation of colleges and universities tells us that there are some differences between different subjects in the field of scientific research and teaching achievements, some of the differences may be great. For example, between mainstream and non-mainstream disciplines, the key disciplines and key disciplines, teachers of specialized course and teachers of public fundamental course, there are considerable differences. Different types of teachers should be carried out different professional title appraisal system and different teaching scientific research evaluation criteria. 
To Change the situation of "appreciate scientific research and despite teaching". Truly implement the idea of teaching as the center, and effectively improve the status of teaching, enrich the dimensions of teaching achievements, improve the level of teaching achievement, increase the weight of assessment of teaching in the teachers evaluation, develop an evaluation policy which make the achievement of teaching and scientific research can be equally treated and can be replaced by each other, make teaching and research have the same value.

To improve the economic incentive for teachers to engage in teaching. Enrich the types of teaching construction projects, such as different levels of key courses, excellent courses, bilingual courses, and textbook constructions, set up various awards for teaching, such as outstanding teachers, backbone teachers, famous teachers, improve teachers' post allowance and class allowance, achieve the positive economic incentives for teachers engaged in teaching work.

The above three measures can promote the teacher to have the positive will to devote all kinds of resources, such as time, energy and funds, etc., to teaching, improve teachers' teaching level, improve the quality of teaching. College, in the case of teachers actively engaged in teaching, is more willing to actively invest more resources, so as to form a virtuous circle, and eventually form a good situation of tripartite win-win for college, teachers and students.

\section{References}

[1] Zhang qiang, Qiao haishu, Chen zhiqiang. Analysis on the Construction of College Teaching Team with Game Theory: From the Perspective of increasing Teaching Input, Journal of Higher Education,Vol.32 No.6,pp.78-83,Jun. 2011.

[2] Li yanhua, Wei jianhua, Game Playing Analysis of the Fund's Input and usage of the University Teaching team: Perspective of the Game Playing between the Government and Universities, Journal of Jiangxi Science \& technology Normal University, No.6, pp.98-102, Dec.2012.

[3] Wu guangmou, Lv zhouxiang, Principles and Application of Game Theory, Southeast University Press, Mar.2009. 